\title{
Interferon beta-1a for COVID-19: critical importance of the administration route
}

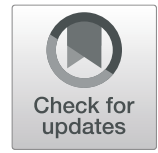

Juho Jalkanen", Maija Hollmén ${ }^{2}$ and Sirpa Jalkanen ${ }^{2 *}$

Type I interferons, especially IFN-beta, have been appointed as potential leading therapeutics to tackle severe COVID-19 and are currently being evaluated in REMAP-CAP and the WHO's Solidarity Trial. As a most recent example, combination treatments with IFN-beta, lopinavir-ritonavir, and ribavirin showed that the arm containing IFN-beta was superior in eliminating the virus from the nasopharyngeal swabs in phase II clinical trial [1]. Recent papers on the matter unfortunately fall short of differentiating between subcutaneous (s.c.) and intravenous (i.v.) administration, which are completely different treatments concerning drug exposure and wanted effects in the lung endothelium, which is under attack in COVID-19 [2]. We wish to highlight the differences of these two treatment methods and also other crucial aspects of IFN-beta treatment for COVID-19 and acute respiratory distress syndrome (ARDS).

A recent report concluded that the pharmacological effects of s.c. vs. i.v. IFN-beta-1a are the same, because they produce similar anti-viral responses [3]. Importantly, however, the pharmacokinetics of s.c. vs. i.v. IFN-beta are complete mirror images, "flip-flops" [4]. Maximum serum concentrations (Cmax) and total exposure through serum concentrations are significantly higher after i.v. than s.c. injections $(p=0.0001)$. Prior corner stone PK studies investigating s.c. vs. i.v. administration of IFN-beta-1a conclude that s.c. administration produces significantly lower drug concentrations and incomplete bioavailability compared to i.v. dosing. The bioavailability via the s.c. route is about one third of that obtained by i.v. injections [4]. For critically ill patients on vasopressors and with very limited peripheral microcirculation, the bioavailability of s.c. dosed IFN-beta becomes even more questionable. IFN-

\footnotetext{
* Correspondence: sirpa.jalkanen@utu.fi

${ }^{2}$ MediCity Research Laboratory and Institute of Biomedicine, University of Turku, Turku, Finland

Full list of author information is available at the end of the article
}

beta is cleared almost solely through its receptor (IFNAR). With s.c. dosing, IFN-beta is slowly taken up by the lymphatic system, from which it enters the blood during a number of hours with modest peak concentrations. In contrast, i.v. dosing achieves high serum concentration and efficiently reaches vast capillary beds of central organs, where it is taken up by its receptors without saturating the body and causing unwanted adverse events. This is an important aspect as endothelial dysfunction is connected to COVID-19 infection [2, 5]. Nonetheless, the purpose of i.v. administered IFN-beta for the treatment of COVID-19 and ARDS is to maximise bioavailability of the drug at the lung vasculature, as well as other vascular beds. This is hardly achieved with s.c. dosing in critically ill patients. IFN-beta increases CD73 in pulmonary capillaries. This is of utmost importance as CD73 is the key enzyme for vascular integrity under hypoxic conditions. The protective effect of IFN-beta on the lung is attributed to the clearance of pro-inflammatory ATP and prothrombotic ADP from circulation and converting them into highly anti-inflammatory adenosine via AMP step by CD73 [6].

It is well known that corticosteroids as immunosuppressors dampen our natural anti-viral responses, and the direct inhibitory effect of corticosteroids on IFN signalling has been reported [7]. Still corticosteroids are widely used to treat ARDS and severe viral respiratory infections even though several studies have shown that corticosteroid use is associated with harm in viral outbreaks such as H1N1 and MERS [8]. In fact, reports on using type I IFNs for the treatment of MERS reveal that the majority of these patients received systemic corticosteroids with IFN. For example, $60 \%$ of MERS patients received corticosteroids with type I IFN [9]. In the recent INTEREST study investigating the use of i.v. IFNbeta-1a for ARDS, the primary analyses did not show any benefit for IFN-beta over placebo [10]. However, 
nearly $60 \%$ of the patients received corticosteroids with IFN-beta. Further studies revealed that corticosteroids block IFN signalling and the upregulation of CD73 expression in human pulmonary endothelial cells, and combining i.v. IFN-beta with systemic corticosteroids may be even more detrimental than corticosteroids alone [11]. These findings suggest that the different anti-inflammatory pathways triggered by IFN-beta and corticosteroids should not be induced at the same time.

Immunomodulation is complex, and timing of the treatments is critical. There are a limited number of direct studies on the timing of immunomodulatory treatments such as IFN-beta, but given our basic understanding of human biology and viral defence, we suggest that IFN-beta should be given early to COVID-19 patients. In mild cases such as in the recent clinical trial, even s.c. administered IFN-beta was effective [1], but in more severe cases, i.v. injections are needed to rapidly reach the endothelium. As ARDS rises together with a cytokine storm, corticosteroids may play a beneficial role during the later fibrotic phase or just by calming down the cytokine storm after IFNs have had their impact. This is supported by Villar et al. who showed that the use of dexamethasone was associated with better survival in ARDS [12]. A notable feature of this study is that the enrolled patients were not on steroids when entering the trial. Thus, initial endogenous IFN responses had not been tampered. Sequential treatment strategy may be the future once we are able to reliably understand the time course of patients' immunological responses.

Severely ill COVID-19 patients with increased levels of plasma cytokines (especially IL-6) show signs of immune exhaustion and poor IFN responses [13]. Even in such cases, these patients would most likely benefit from IFNbeta, because it is the most potent anti-viral and antiinflammatory agent of all interferons. It can induce the desired immune boost, but simultaneously downregulate IL-6 and IL-8 [14] and impair extravasation of neutrophils into lungs [15].

\section{Conclusions}

IFN-beta is now among the leading candidates to treat COVID-19 in various clinical trials, and i.v. and s.c. routes of administration are considered to be equal. This is not the case due to the different bioavailabilities of IFN-beta via i.v. and s.c. injections in target organs. This aspect needs to be taken seriously, when critically ill patients with compromised peripheral circulation are treated.
Authors' contributions

All authors contributed to the writing of this comment; the funding agencies did not have any role. The authors read and approved the final manuscript.

\section{Funding}

$\mathrm{MH}$ and SJ are supported by the Finnish Academy and Sigrid Juselius Foundation.

\section{Availability of data and materials \\ NA}

\section{Ethics approval and consent to participate}

NA

\section{Consent for publication}

NA

\section{Competing interests}

$\mathrm{JJ}$ is an employee and shareholders of Faron Pharmaceuticals. MH and SJ own stocks of Faron Pharmaceuticals, and SJ has a patent (US 7534423).

\section{Author details}

${ }^{1}$ Faron Pharmaceuticals Ltd., Turku, Finland. ${ }^{2}$ MediCity Research Laboratory and Institute of Biomedicine, University of Turku, Turku, Finland.

Received: 25 May 2020 Accepted: 28 May 2020

Published online: 12 June 2020

\section{References}

1. Cheung KS, Hung IF, Chan PP, Lung KC, Tso E, Liu R, Ng YY, Chu MY, Chung TW, Tam AR et al: Gastrointestinal manifestations of SARS-CoV-2 infection and virus load in fecal samples from the Hong Kong cohort and systematic review and meta-analysis. Gastroenterology 2020; epub ahead.

2. Ackermann M, Verleden SE, Kuehnel M, Haverich A, Welte T, Laenger F, Vanstapel A, Werlein C, Stark H, Tzankov A et al: Pulmonary vascular endothelialitis, thrombosis, and angiogenesis in Covid-19. N Engl J Med. 2020; epub ahead.

3. Sallard E, Lescure FX, Yazdanpanah Y, Mentre F, Peiffer-Smadja N. Type 1 interferons as a potential treatment against COVID-19. Antivir Res. 2020;178: 104791.

4. Mager DE, Jusko WJ. Receptor-mediated pharmacokinetic/ pharmacodynamic model of interferon-beta 1a in humans. Pharm Res. 2002; 19(10):1537-43.

5. Varga Z, Flammer AJ, Steiger P, Haberecker M, Andermatt R, Zinkernagel AS, Mehra MR, Schuepbach RA, Ruschitzka F, Moch H. Endothelial cell infection and endotheliitis in COVID-19. Lancet. 2020;395(10234):1417-8.

6. Eltzschig HK, Sitkovsky MV, Robson SC. Purinergic signaling during inflammation. N Engl J Med. 2012;367(24):2322-33.

7. Flammer JR, Dobrovolna J, Kennedy MA, Chinenov Y, Glass CK, Ivashkiv LB, Rogatsky I. The type I interferon signaling pathway is a target for glucocorticoid inhibition. Mol Cell Biol. 2010:30(19):4564-74.

8. Russell CD, Millar JE, Baillie JK. Clinical evidence does not support corticosteroid treatment for 2019-nCoV lung injury. Lancet. 2020;395(10223): 473-5.

9. Arabi YM, Shalhoub S, Mandourah Y, Al-Hameed F, Al-Omari A, Al Qasim E, Jose J, Alraddadi B, Almotairi A, Al Khatib K, et al. Ribavirin and interferon therapy for critically ill patients with middle east respiratory syndrome: a multicenter observational study. Clin Infect Dis. 2020:70(9):1837-44.

10. Ranieri VM, Pettilä V, Karvonen MK, Jalkanen J, Nightingale P, Brealey D, Mancebo J, Ferrer R, Mercat A, Patroniti N et al: Effect of intravenous interferon $\beta$-1a on death and days free from mechanical ventilation among patients with moderate to severe acute respiratory distress syndrome: a randomized clinical trial. JAMA 2020; epub ahead.

11. Jalkanen J, Pettilä V, Huttunen T, Hollmén M, Jalkanen S: Glucocorticoids inhibit type I IFN beta signaling and the upregulation of CD73 in human lung. Intensive Care Med. 2020; epub ahead.

12. Villar J, Ferrando C, Martínez D, Ambrós A, Muñoz T, Soler JA, Aguilar G, Alba F, González-Higueras E, Conesa LA, et al. Dexamethasone treatment for the acute respiratory distress syndrome: a multicentre, randomised controlled trial. Lancet Respir Med. 2020;8(3):267-76. 
13. Blanco-Melo D, Nilsson-Payant BE, Liu WC, Uhl S, Hoagland D, Møller R, Jordan TX, Oishi K, Panis M, Sachs D et al: Imbalanced host response to SARS-CoV-2 drives development of COVID-19. Cell 2020; epub ahead.

14. Laver T, Nozell SE, Benveniste EN. IFN-beta-mediated inhibition of IL-8 expression requires the ISGF3 components Stat1, Stat2, and IRF-9. J Interf Cytokine Res. 2008;28(1):13-23.

15. Kiss J, Yegutkin GG, Koskinen K, Savunen T, Jalkanen S, Salmi M. IFN-beta protects from vascular leakage via up-regulation of CD73. Eur J Immunol. 2007;37(12):3334-8.

\section{Publisher's Note}

Springer Nature remains neutral with regard to jurisdictional claims in published maps and institutional affiliations. 